\title{
Histórico, atualidades e desempenho produtivo da agricultura fluminense.
}

Elton de Oliveira ${ }^{1}$, Adriana Maria de Aquino ${ }^{2}$, Renato Linhares de Assis $^{3}$, Luan Alves de Souza ${ }^{4}$, Flávio Castro da Silva ${ }^{5}$

\section{RESUMO}

Simultaneamente, em uma mesma época dos anos 1800, duas políticas ligadas à exploração da terra, deram início ao processo de formação da agricultura, nas regiões montanhosas do estado do Rio de Janeiro. Com objetivo de contextualizar historicamente o desenvolvimento da agricultura fluminense e avaliar o seu desempenho produtivo, foram realizadas uma pesquisa na literatura e uma análise de dados quantitativos da atual produção agrícola. Verificou-se que o desenvolvimento desta atividade foi gerado dentro de uma diversidade de ambientes, pessoas, espécies vegetais, estratégias, políticas e situações econômicas que contribuiu para moldar a sua conformação atual, com características, dinâmica agrária e desempenho, diferenciados. Foi identificado que as regiões serrana e sul, apresentaram os maiores faturamentos por hectare e, também, os municípios com maior diversidade produtiva.

Palavras-chaves: história agroambiental; ambientes de montanha; agrobiodiversidade.

\footnotetext{
1 Doutor em Ciência, Tecnologia e Inovação em Agropecuária (Universidade Federal Rural do Rio de Janeiro - UFRRJ), Técnico em Agropecuária do Departamento de Engenharia Agrícola e Meio Ambiente da Universidade Federal Fluminense, Brasil, ORCID: https://orcid.org/0000-0001-76490745, e-mail: oliveruff2@gmail.com

2 Doutora em Ciência do Solo (Universidade Federal Rural do Rio de Janeiro - UFRRJ), Pesquisadora da EMBRAPA Agrobiologia, Núcleo de Pesquisa e Treinamento para Agricultores da Região Serrana Fluminense, Brasil, ORCID: https://orcid.org/0000-0003-3718-4512, e-mail: adriana.aquino@embrapa.br

${ }^{3}$ Doutor em Desenvolvimento Econômico, Espaço e Meio Ambiente (Universidade Estadual de Campinas - UNICAMP), Pesquisador da EMBRAPA Agrobiologia, Núcleo de Pesquisa e Treinamento para Agricultores da Região Serrana Fluminense, Brasil, ORCID: https://orcid.org/0000-0003-42285166, e-mail: renato.assis@embrapa.br

${ }^{4}$ Mestre em Engenharia de Biossistemas (Universidade Federal Fluminense - UFF), Engenheiro Agrícola e Ambiental pela Universidade Federal Fluminense, Brasil, ORCID: https://orcid.org/0000-0003-4558-2182, e-mail: luan_souza@id.uff.br

5 Doutor em Engenharia Agrícola (Universidade Federal de Lavras - UFLA), Professor adjunto da Universidade Federal Fluminense - UFF, Brasil, ORCID: https://orcid.org/0000-0003-1366-9806, e-mail: flaviocastro@id.uff.br
} 
partir do contexto da questão agrária na Europa e da situação política do Brasil,
no início do século XIX, o Rio de Janeiro passa a sofrer influências que
Lestimulam o desenvolvimento de sua agricultura. Na história agroambiental brasileira considerada, ressaltam-se duas políticas públicas agrícolas fundamentais, concebidas simultaneamente, que influenciaram na formação da sua agricultura. Uma estruturou a cultura do café e a outra marcou a colonização com imigrantes europeus, ambas ocorreram nas regiões montanhosas do estado do Rio de Janeiro, no século XIX. A cafeicultura contribuiu para uma produção especializada e insustentável, enquanto a colonização com imigrantes buscou a produção de alimentos para a crescente população. Essas ações deram início a um processo de hibridação que veio contribuir para uma pluralidade genética e cultural, na construção de um território, que mesmo de forma conturbada, inclusive nas relações com a natureza, originou, nos dias de hoje, o robusto vigor da herança dessa região.

O objetivo desse trabalho foi de contextualizar historicamente o desenvolvimento da agricultura, nas regiões montanhosas do estado do Rio de Janeiro e avaliar o seu atual desempenho produtivo. Para tal, foram elaboradas uma revisão da literatura histórica e uma análise de dados quantitativos. Os resultados encontrados podem auxiliar no entendimento da sua atualidade e na identificação das regiões com os melhores desempenhos produtivos.

\section{O BRASIl COLÔNIA NO CONTEXTO DO MUNDO, NO SÉCULO XIX}

Nos anos 1800, grande parte do mundo ocidental tinha a atividade agrária como prioritária. No entanto, a partir de 1851, com a revolução industrial na Inglaterra, a população urbana veio a ultrapassar a rural. No continente europeu, economistas seguidores da escola do francês François Quesnay (1694-1774), contrários ao Mercantilismo inglês, preconizavam que a terra era a única fonte de riquezas da nação. Sendo a terra e o seu aluguel, as únicas fontes de renda líquida, gerando um conflito entre os proprietários e os que trabalhavam no seu cultivo, propiciando grandes 
desigualdades e revoltas sociais. Estes distúrbios constituíram multidões de miseráveis, contribuindo para as emigrações transatlânticas em massa, a partir de $1815^{6}$.

As colônias europeias nas américas possuíam vastas extensões de terras, ricas em valiosos recursos naturais que eram explorados de forma degradante. Portugal, desde o século XIV, tinha criado a Lei das Sesmarias de 1375, a fim de normatizar a distribuição de terras destinadas à produção agrícola, visando combater a crise agrícola e econômica que atingia o país e a Europa. O estado, sem capacidade para organizar a produção de alimentos, passa a delegar essa função à particulares. Neste sistema de Sesmarias, era obrigatório cultivar o solo num determinado prazo, sob pena de cancelamento da concessão. O sistema de sesmarias foi utilizado na América portuguesa a partir do século XVI. Dessa forma, iniciou-se um processo agrícola com a implantação do Plantation, sistema agrícola amplamente utilizado durante a colonização europeia na América, que utilizava a mão de obra escrava em larga escala. Nesse período colonial, este sistema agrícola foi usado para a formação de grandes latifúndios, principalmente em plantações de cana de açúcar e café. As sesmarias incorporaram a exigência do pagamento do dízimo à Ordem de Cristo, um imposto que incidia sobre a produção da agricultura e da pecuária coloniais?

Em 21 de novembro de 1806, na França, Napoleão decretou o bloqueio continental com a intenção de prejudicar a Inglaterra. Para que esse bloqueio tivesse efeito, seria necessário contar com o apoio de todos os países europeus. Dependente de suas relações com a Inglaterra, Portugal ficou no meio de um fogo cruzado. Ao mesmo tempo em que se submetia às exigências do governo francês, assinava uma Convenção secreta com a Inglaterra, que previa o embarque da família real para o Brasil, no caso de uma invasão francesa. Ao tomar conhecimento da Convenção PortugalInglaterra, Napoleão assinou com a Espanha o Tratado de Fontainebleau que estabelecia a invasão e desmembramento de Portugal, a extinção da dinastia Bragança e a divisão das colônias portuguesas entre França e Espanha. A família real então, em vinte e nove de outubro de 1807, a bordo de naus portuguesas protegidas por uma divisão Inglesa, deixou Lisboa. Aportou em Salvador no dia vinte e dois de janeiro de

\footnotetext{
${ }^{6}$ Eric John Ernest Hobsbawm, A era das revoluções: Europa, 1789-1848 (Rio de Janeiro: Paz e Terra, 1989), 532p.

7 Luís Henrique Menezes Fernandes, Um Governo de Engonços: Metrópole e Sertanistas na Expansão dos Domínios Portugueses aos Sertões do Cuiabá (1721-1728) (Curitiba: Editora Prismas, 2015), 197p.
} 
1808, vindo em março para o Rio de Janeiro. D João VI passa a governar como rei e é nomeado regente do reino com sagração e aclamação em 6 de fevereiro de 1818, após a morte de sua mãe Dona Maria, Rainha de Portugal, em 20 de março de 1816. No Brasil, recebeu o título de imperador e a seguir o de Rei de Portugal, Brasil e Algarves ${ }^{8}$.

Em um documento histórico de 1875, foi relatado a riqueza e os benefícios da natureza brasileira, onde os recursos naturais, ainda eram enxergados de forma inesgotável. Na página 76 desse trabalho, foi descrita a Província do Rio de Janeiro: "Nenhuma região do Globo sobre uma igual extensão apresenta uma maior variedade de formas vegetaes". Diz ainda: "Consistindo sobretudo em profundos vales e altas montanhas, algumas com 7000 pés de elevação acima do nível do mar, oferece necessariamente, uma variedade de terrenos e situações favoráveis às diferentes espécies vegetaes" 9 .

\section{O Processo de Desenvolvimento da Cafeicultura}

A partir de 1760, no Brasil, observou-se o declínio da economia do ouro de Minas Gerais, iniciou-se a redução da sua produção, com consequente impacto na economia colonial, que também tinha o açúcar e o algodão como principais produtos de exportação, porém, como mercadorias de menor valor no exterior. A decadência do ouro ocorreu juntamente com a decadência do açúcar, situação que perdurou até o início da expansão cafeeira ${ }^{10}$.

Por volta de 1730, o café chegou ao Brasil, com sementes trazidas das Guianas, pelo oficial Francisco de Melo Palheta, para o estado do Pará. Em seguida, foi levado para o Maranhão e trinta anos depois, para a capital da província do Rio de Janeiro. A partir de 1760, o cultivo inicial, ocorreu nos morros da cidade e na região do Mendanha, na Baixada Fluminense. Os caminhos já abertos, para o carregamento do ouro que se exauria, permitiram que esta nova riqueza, o café, povoasse as terras do Vale do Paraíba do Sul. Sendo cultivado por volta de 1780, nas terras do município de Paty do Alferes,

\footnotetext{
8 Laurentino Gomes, 1808: Como uma rainha louca, um príncipe medroso e uma corte corrupta enganaram Napoleão e mudaram a História de Portugal e do Brasil (São Paulo: Ed. Globo, 2014), 382p.

${ }^{9}$ Nicolau Joaquim Moreira, Indicações agrícolas para os imigrantes que se dirigem ao Brasil (Rio de Janeiro: Imperial Instituto Artístico, 1875).

10 Celso Furtado, Formação Econômica do Brasil (São Paulo: Companhia Editora Nacional, 1959), 242p.
} 
que na época, integrava o município de Vassouras. Assim, o plantio dos primeiros cafezais comerciais ocorreu em terras localizadas nas imediações dos "Caminhos do Ouro" para a cidade do Rio de Janeiro. Inicialmente, os escravos utilizados nessa atividade, eram procedentes da decadente atividade mineradora. Essa região possuía pousos de tropeiros e sítios com uma agricultura que fornecia gêneros agrícolas como feijão, milho e mandioca, para a capital da colônia. Com o apoio da coroa, novas estradas logo surgiram e as antigas foram melhoradas ou ampliadas com o objetivo de facilitar o escoamento desta importante carga, que era transportada em lombo de mulas ${ }^{11}$.

As áreas de produção cafeeira foram sendo implantadas em regiões de maior elevação, pelo eixo do rio Paraíba do Sul. Essa expansão aconteceu de maneira conflituosa, dizimando de forma violenta, os índios Puris e Corodos que habitavam essa região, bem como expulsando os posseiros que cultivavam lavouras de subsistência ${ }^{12}$.

Esse processo de expansão da cafeicultura ocorreu em propriedades rurais, caracterizadas por grandes extensões de terras, na região próxima à Corte, que foram destinadas a elementos privilegiados pela Coroa Portuguesa, tais como: membros da burocracia governamental, antigos mineradores de Minas Gerais e comerciantes do Rio de Janeiro. Esses conheciam os trâmites legais para a obtenção de terra, além dos recursos financeiros suficientes para assumirem as sesmarias ${ }^{13}$.

Com isso, restaram aos sitiantes agricultores, áreas periféricas, onde desenvolviam uma produção de subsistência e excedentes para abastecimento do mercado local, muitas vezes também utilizando trabalho escravo. Assim, através da venda de gêneros alimentícios, obtinham seus ganhos e tentavam adquirir terras para seus cultivos. Porém, isso ocasionou muitos conflitos entre as partes interessadas, levando o governo português em 1817 a tentar regularizar, através de demarcações e registros, todas as propriedades, independentemente da origem das ocupações. Em 17 de julho de 1822, o Príncipe Regente D. Pedro decretou a extinção da concessão de

\footnotetext{
${ }^{11}$ Afonso de Escragnolle Taunay, Pequena História do Café no Brasil (1727-1937), (Rio de Janeiro: Departamento Nacional do Café, 1945), 558p. 12 Wilson Vieira, "Apogeu e decadência da cafeicultura fluminense (1860 - 1930)" (Dissertação de Mestrado em História Econômica Universidade Estadual de Campinas -UNICAMP, 2000).

13 Humberto Fernandes Machado, Escravos, Senhores e Café. A Crise da Cafeicultura Escravista do Vale do Paraíba Fluminense, 1860-1888 (Niterói: Clube de Literatura Cromos, 1993), 144p.
} 
sesmarias, dado às disputas existentes, principalmente nas terras do Vale do rio Paraíba do Sul ${ }^{14}$.

Dessa forma, a expansão da atividade cafeeira no Brasil do século XIX é explicada pela ocupação das abundantes terras próximas dos portos de embarque para o exterior, notadamente na região do Vale do rio Paraíba do Sul. O transporte do café dessa região até o porto era feito em lombo de mulas, até 1852, quando foi inaugurada a Estrada de Ferro D. Pedro II. Isso reduziu os custos de transporte de uma produção em larga escala, que se valia ainda de mão de obra escrava para reduzir os seus custos. Porém, eram usadas técnicas predatórias no cultivo, sem nenhum cuidado com a terra, esgotando a fertilidade natural do solo e intensificando a erosão. Essa foi a base que sustentou a lucratividade e ampliação da cafeicultura no país, possibilitando o enfrentamento, com sucesso, da concorrência dos demais países produtores ${ }^{15}$. Esse quadro de ascensão cafeeira regrediu a partir da década de 1850, devido à proibição legal do tráfico negreiro pela Lei Euzébio de Queiroz, de 4 de setembro de 1850. Com essa lei, o preço do escravo se elevou e a expansão cafeeira ocorreu com custos crescentes ${ }^{16}$.

Os processos agrícolas rudimentares empregados na cafeicultura fluminense, as condições inadequadas de manejo do solo, a topografia com declives acentuados, com a consequente erosão e exaustão das terras causaram esgotamento crescente da atividade cafeeira na região ocidental do Vale do rio Paraíba do Sul (Resende, Barra Mansa, Vassouras, Miguel Pereira, entre outros municípios atuais). O deslocamento para a região oriental (Paraíba do Sul, Três Rios, Petrópolis, Cantagalo), a procura de terras com maior fertilidade natural, causou aumento nos custos de produção, principalmente de transporte. A produção cafeeira da região de Cantagalo, ainda se estendeu para Nova Friburgo, Bom Jardim, Cordeiro, Carmo, Duas Barras, sendo a base da atividade econômica cafeeira do Barão de Nova Friburgo que veio a ser um dos homens mais ricos do Brasil, na segunda metade do século XIX ${ }^{17} 18$.

Portanto, a cafeicultura fluminense atingiu seu nível máximo de produção em 1882. A partir daí, assistimos à sua derrocada, cujas causas, oriundas desde 1850,

\footnotetext{
14 Lígia Osorio Silva, Terras Devolutas e Latifúndio: Efeitos da Lei de 1850 (Campinas: Editora da UNICAMP, 1996), 373p.

15 João Manuel Cardoso de Mello, O Capitalismo Tardio (São Paulo: Editora Brasiliense, 1982), 182p.

16 Wilson Vieira, "Apogeu e decadência da cafeicultura fluminense (1860 - 1930)" (Dissertação de Mestrado em História Econômica -

Universidade Estadual de Campinas -UNICAMP, 2000).

17 Stanley Stein, Grandeza e Decadência do Café no Vale do Paraíba (São Paulo: Editora Brasiliense, 1961), 372p.

${ }^{18}$ Afonso de Escragnolle Taunay, Pequena História do Café no Brasil (1727-1937), (Rio de Janeiro: Departamento Nacional do Café, 1945), 558p.
} 
estavam no custo crescente do escravismo, a partir do fim do tráfico negreiro, que ainda determinou a crescente perda de eficiência, devido ao envelhecimento da mão de obra escrava remanescente. Esse processo foi potencializado pelo uso de técnicas de produção agrícola que conduziam a degradação dos solos, e o aumento dos problemas fitossanitários nas lavouras ${ }^{19}$.

Assim, no período entre os anos de 1800-1889, ocorreu a ascensão e a decadência da atividade cafeeira no Vale do rio Paraíba do Sul fluminense. "A escravidão e o café, foram ao mesmo tempo, alimento e veneno para essa região, que perdeu sua condição de produtora de café para o oeste paulista"20.

\section{O Processo de Desenvolvimento da Horticultura}

Durante esse mesmo período, ainda na segunda década do século XIX, o rei D. João VI acreditava que somente com a vinda de colonos de outras nações, seria possível construir um futuro virtuoso para o Brasil. Com esse pensamento, ele entendeu que deveria promover a posse de terras para instalação de colonos europeus no país ${ }^{21}$.

Assim sendo, foram divulgadas as inúmeras vantagens que o rei prometia, aos que se inscrevessem nesse projeto: despesas de viagem pagas, alojamentos, terras, sementes, animais fornecidos gratuitamente pelo governo, subsídios e salários no período de instalação no país, isenção de serviço militar e todos os impostos pessoais e territoriais, exercício inteiramente livre de religião, entre outras. Informações muito atraentes, sobretudo para pessoas que acabavam de atravessar na Suiça, dois anos desastrosos em todos os sentidos: o de 1816, chamado de o Ano da Miséria, e, o de 1817, chamado de o Ano da Carestia ${ }^{22}$.

Em 1817, Nicolau Sebastião Gachet foi designado para assumir o projeto de emigração. Foram então lavrados os termos definitivos para o embarque dos imigrantes, obedecendo a uma série de condições pelas quais o rei português concedeu ao estabelecimento de uma colônia para um grupo de cem famílias de suíços. Gachet

\footnotetext{
19 Stanley Stein, Grandeza e Decadência do Café no Vale do Paraíba (São Paulo: Editora Brasiliense, 1961), 372p.

20 Cristiano Mascaro, Tasso Fragoso Pires, Mary del Priore, Roberto Conduru, Marta Fadel, Fazendas do Império, (Rio de Janeiro: Edições Fadel,

2010), 312p.

${ }^{21}$ Agenor de Roure, "O Centenário de Nova Friburgo", Revista do Instituto Histórico Geographico Brasileiro 83 (1918): 243-266.

22 Pedro Cúrio, Como surgiu Friburgo (Esboço Histórico e Episódico) - 1818-1840 (SEDEGRA S/A, 1974), 176p.
} 
foi incumbido de implementar uma colônia suíça na Fazenda do Morro Queimado, situada onde hoje está parte do município de Nova Friburgo que ficava, na época, a cinco dias de distância do Rio de Janeiro. A ideia inicial de Sua Majestade, era localizar a colonização na cidade do Rio de Janeiro, na região de Santa Cruz, em Fazenda do próprio D. João VI, mas o clima das serras teve peso na decisão, quando Gachet ponderou que a aclimatação em campos encharcados e de clima quente de Santa Cruz não seria favorável ${ }^{23} 24$.

A região denominada Morro Queimado, assim chamada pela existência, nessa área, de montes de formação rochosa escura, cuja vegetação, em determinadas épocas do ano, era destruída por incêndios naturais. Esta região fazia parte do distrito de Cantagalo (antes Cantagalo das Novas Minas dos Sertões de Macacu, Arraial de Cantagalo e Vila de São Pedro de Cantagalo). Naquela época, era uma terra inóspita, até então habitada por índios (Caiapós, Coroados, Goitacás, Sacarus, Puris e Botocudos), coberta por florestas incluídas na faixa de Mata Atlântica do atual estado do Rio de Janeiro, explorada por garimpeiros, contrabandistas de ouro e de pedras preciosas 2526 .

Em 1819 chegou ao Brasil, a primeira leva de imigrantes suíços, autorizados a entrar no país pela coroa portuguesa, estabelecendo-se no local que, em 1820, recebeu o status de Vila de Nova Friburgo. Logo após a independência do Brasil, os suíços foram sucedidos, em 1823, por imigrantes alemães ${ }^{27} 28$.

Contudo, muitos colonos receberam lotes com condições de solo inadequadas para a atividade agrícola e foram migrando para a região, onde hoje, se encontra o município de Cantagalo, na esperança de encontrar terras aptas para o cultivo do café. Outros mudaram-se para áreas dos atuais distritos de Lumiar e São Pedro da Serra em Nova Friburgo, onde adotaram práticas tradicionais de cultivos para produção de subsistência. Um número indeterminado de colonos suíços e alemães decidiu ir

\footnotetext{
23 Jules Conus, História da Emigração Friburguense para o Brasil, 1819 a 1820. Trad. José Cortes Coutinho (Nova Friburgo: Typographya da Sociedade Editora e Impressora de Friburgo, 1918), 34p.

${ }^{24}$ Carlos Rodolpho Fischer, Uma História em Quatro Tempos (Nova Friburgo: Fábrica de Rendas Arp S.A, 1986), 142p.

${ }^{25}$ Maria Janaina Botelho Corrêa, Histórias e memória de Nova Friburgo (Rio de Janeiro: Educam, 2011), 448p.

${ }^{26}$ Thomé Maria de Fonseca e Silva, "Breve Notícia sobre a Colônia de Suíços fundada em Nova Friburgo", Revista Trimensal de História e Geographia 5, XII, 14 (1849): 136-142.

27 Jules Conus, História da Emigração Friburguense para o Brasil, 1819 a 1820. Trad. José Cortes Coutinho (Nova Friburgo: Typographya da Sociedade Editora e Impressora de Friburgo, 1918), 34p.

${ }^{28}$ Antonio Carlos Frossard, "Pedagogia da alternância e articulação dos agentes formativos de técnicos em agropecuária: interação entre educação do campo e desenvolvimento rural sustentável em Nova Friburgo (Brasil) e Lobos (Argentina)" (Tese de Doutorado em Ciência Tecnologia e Inovação em Agropecuária, Universidade Federal Rural do Rio de Janeiro - UFRRJ, 2014)
} 
trabalhar como empregados em fazendas já estabelecidas como a Fazenda March (futura Teresópolis), Fazenda Mendes e Fazenda Machado (distrito de Campo do Coelho em Nova Friburgo), iniciando um lento processo de substituição da mão-de-obra $\operatorname{escrava}^{29}$.

\section{A DECADÊNCIA DAS POLÍTICAS DE EXPLORAÇÃO AGRÍCOLA DO PASSADO}

Voltando à segunda metade do século XIX, pode-se verificar que, com o crescente encarecimento da mão de obra escrava, decorrente da extinção do tráfico negreiro, a agricultura cafeeira tendeu à especialização, reduzindo as atividades destinadas aos cultivos de alimentos. Assim, os gêneros alimentícios consumidos nas fazendas cafeeiras passaram a ser comprados. Esse fato contribuiu para o aumento dos preços desses alimentos no mercado ${ }^{30}$. Conforme pode ser verificado na Tabela1 que apresenta a evolução crescente dos preços dos alimentos na cidade do Rio de Janeiro, pela inflação de demanda, entre os anos de 1850 e 1859 (Tabela 1).

Tabela 01. Preços dos alimentos no Rio de Janeiro por ano, valores em Réis.

\begin{tabular}{llll}
\hline \multirow{2}{*}{ MERCADORIA } & Preços & & \\
\cline { 2 - 4 } & $1850 / 1851$ & $1854 / 1855$ & $1858 / 1859$ \\
\hline Arroz (arroba) & $1 \$ 520$ & $1 \$ 410$ & $3 \$ 300$ \\
Açúcar (arroba) & $1 \$ 770$ & $2 \$ 050$ & $3 \$ 750$ \\
Carne Seca (arroba) & $2 \$ 720$ & $2 \$ 830$ & $5 \$ 500$ \\
Feijão (alqueire) & $2 \$ 300$ & $3 \$ 980$ & $4 \$ 980$ \\
Milho (alqueire) & $1 \$ 150$ & $1 \$ 530$ & $3 \$ 750$ \\
Toucinho (arroba) & $3 \$ 540$ & $7 \$ 980$ & $8 \$ 500$ \\
\hline
\end{tabular}

Fonte: Adaptado de Stein ${ }^{31} 1961$.

Ressalta-se ainda que com o fim do tráfico negreiro, o fazendeiro produtor de café, para comprar mais escravos, a preços cada vez mais elevados, confiava suas safras futuras para liquidar suas dívidas, as empenhando para obter mais dinheiro. Além disso,

\footnotetext{
${ }^{29}$ Pierre-Nicolas Grisel, "La possibilité dúne transition agroécologique: Une analyse des déterminants économiques, écologiques et institutionnels de l'adoption de pratiques agricoles alternatives dans une communauté a'agriculteurs familiaux au Brésil" (Tese de Doutorado, Paris, Université de Versailles Saint Quentin en Yvelines, 2013).

30 Stanley Stein, Grandeza e Decadência do Café no Vale do Paraíba (São Paulo: Editora Brasiliense, 1961), 372p.

31 Stanley Stein, Grandeza e Decadência do Café no Vale do Paraíba (São Paulo: Editora Brasiliense, 1961), 372p.
} 
avançava, predatoriamente, sobre as matas para plantar mais café, colocando a economia cafeeira do Vale do rio Paraíba do Sul, em um ciclo de efeito deletério ${ }^{32}$

Enquanto isso, os pequenos sitiantes, com pequenas lavouras situadas próximas das grandes propriedades cafeeiras, enfrentaram a falta de acesso ao crédito, aliado a crescente elevação do preço da mão-de-obra escrava. Assim, à medida que se avançou pela década de 1850, a cultura do café tomou o espaço de outras culturas, preocupando as autoridades da Província do Rio de Janeiro, a ponto de que no Relatório de 1857, o Presidente alertar sobre o desaparecimento das culturas da cana-de-açúcar, do arroz, do feijão, do milho e da mandioca. Passando esta província, da condição de exportadora, para importadora de alimentos ${ }^{33}$.

Sendo assim, em meados da década de 1870, a Revista Agrícola anunciava que a agricultura brasileira estava em crise, afirmando que, como herança desse processo histórico, chegou-se a uma agricultura em profundo estado de decadência ambiental, caracterizando o café como cultura esgotadora ${ }^{34}$. "Em um século, o Município de Vassouras e a maior parte do vasto Vale do Paraíba foram palco de um completo ciclo econômico que principiou com a floresta tropical e terminou com morros pelados e erodidos" 35 .

Portanto, a disponibilidade de áreas para colonização e expansão da agricultura estava no interior, notadamente nas regiões montanhosas fluminenses, mas sem acesso a transportes para escoar a produção agrícola. Pode-se verificar, desde 1819, a tentativa de alojar colônias de imigrantes europeus, visando melhorar a produção de alimentos, com uma agricultura diversificada, em pequenas propriedades e com mão de obra familiar. Sendo constatado que a formação desse território se deu de forma conturbada, tanto no ambiente como na saúde dos seus agricultores ${ }^{36}$.

Desse modo, pode-se observar que a dicotomia das políticas, ressaltadas no texto, ora de forma antagônica, sempre buscaram, mesmo que em escalas discrepantes,

34 José Augusto Pádua, Um Sopro de Destruição: pensamento político e crítica ambiental no Brasil escravista (1786-1888) (Rio de Janeiro: Zahar, 2002), 318p.

35 Stanley Stein, Grandeza e Decadência do Café no Vale do Paraíba (São Paulo: Editora Brasiliense, 1961), 372p.

${ }^{36}$ Armando Cypriano Pires, "Dados, Fatos e Falas: Histórias "contadas" sobre Saúde e Trabalho" (Dissertação de Mestrado, Escola Nacional de Saúde Pública Sergio Arouca - ENSP - FIOCRUZ, Rio de Janeiro, 1996) 
se complementar. Onde, conflitos e dilemas desses dois mundos ecoam até os dias de hoje.

Contudo, percebe-se que todas essas iniciativas, tiveram consequências e, também, resultados positivos, nessas regiões. Deram condições para a disseminação de culturas, técnicas, conhecimentos, oportunidades, expectativas que de uma forma ou de outra, contribuiu para a construção de um território calcado na diversidade, com um ambiente natural compartimentado pelo relevo, retalhado, composto por muitas propriedades de pequeno porte, com muitos cultivos diferentes, propenso ao minifúndio agrobiodiverso.

Essa agrobiodiversidade pode ser definida como o conjunto de espécies e componentes da biodiversidade conservada, manejada e utilizada por agricultores, sendo a parte agrícola da biodiversidade, formada pelas plantas de interesse das pessoas, que, por isso, as cultivam. Portanto, resultante do relacionamento, ao longo do tempo, do ser humano com a natureza, por meio da prática de domesticação de plantas e da agricultura. ${ }^{37} 3839$

\section{CONTEXTO ATUAL DA AGRICULTURA FLUMINENSE}

Com o passar dos anos, apesar das dificuldades, os agricultores que se estabeleceram nessa região, encontraram as condições propícias para a implantação de um processo dinâmico de produção agrícola, que se manteve, evoluindo com poucas mudanças até aproximadamente os anos $1950^{40}$. A partir de então, principalmente nos anos 1970, começou uma transição para as técnicas e inovações advindas da então chamada Revolução Verde. Assim, foram introduzidas as técnicas de preparo de solo com moto mecanização, uso de sementes melhoradas, técnicas de irrigação,

\footnotetext{
${ }^{37}$ Rubens Onofre Nodari, Miguel Pedro Guerra, “A agroecologia: estratégias de pesquisa e valores”, Estudos Avançados 29,83 (2015): $183-207$. 38 BRASIL, MMA - Ministério do Meio Ambiente. Agrobiodiversidade, 2017. Disponível em: <http://www.mma.gov.br/biodiversidade/conservacao-epromocao-do-uso-da-diversidade-genetica/agrobiodiversidade>. Acesso em: 21 jan. 2017.

39 BRASIL, EMBRAPA - Empresa Brasileira de Pesquisa Agropecuária. Conceito de Agrobiodiversidade, 2019. Disponível em: $<$ https://www.embrapa.br/contando-ciencia/agricultura/-/asset_publisher/FcDEMJlbvFle/content/o-que-e-agrobiodiversidade1355746?inheritRedirect=false>. Acesso em: $21 \mathrm{fev} 2019$.

40 Antonio Carlos Frossard, "Pedagogia da alternância e articulação dos agentes formativos de técnicos em agropecuária: interação entre educação do campo e desenvolvimento rural sustentável em Nova Friburgo (Brasil) e Lobos (Argentina)" (Tese de Doutorado em Ciência Tecnologia e Inovação em Agropecuária, Universidade Federal Rural do Rio de Janeiro - UFRRJ, 2014)
} 
fertilização química e uso de agrotóxicos. Também ocorreram mudanças na infraestrutura, com a abertura de estradas para o escoamento da produção, favorecendo a transição para uma agricultura nos moldes que se tem hoje: produção de hortaliças com base no elevado aporte de agroquímicos e uso intensivo do solo ${ }^{41}$.

Dessa forma, com o crescimento das famílias dos produtores e o processo de sucessão, as propriedades foram sendo divididas a cada geração, ocasionando na redução gradual do tamanho das propriedades. Também é observado, em função da restrição de espaços adequados disponíveis para a produção agrícola, o uso intensivo das áreas e restrições ao pousio ${ }^{42}$.

Nos dias de hoje, a necessidade dos sistemas produtivos agrícolas buscarem: produtividade, que indica a obtenção da maior quantidade de produtos ou energia, ou valor da produção por unidade de insumos e recursos aplicados à produção; estabilidade, que se refere à constância da produtividade frente às flutuações normais do clima; sustentabilidade, que está associada à habilidade do sistema para manter a produtividade quando sujeito às forças normais de flutuação do ambiente; resiliência, que diz respeito à capacidade do sistema em reagir, em menor tempo, a determinado distúrbio; e invulnerabilidade, ou seja, quando a diversidade de produtos reduz o grau com que o sistema é vulnerável ao distúrbio ${ }^{43}$.

No entanto, uma visão mais ampla, inclui o conceito de sustentabilidade nos agroecossistemas do século XXI, que devem ser capazes de, ao mesmo tempo, maximizar a quantidade de produtos agrícolas de elevada qualidade e conservar os recursos do sistema. O desenvolvimento rural sustentável depende da formulação de uma agenda que contemple os seguintes aspectos: conservação da biodiversidade e dos serviços ambientais, redução da poluição e contaminação do ambiente e do homem, conservação e melhoria da qualidade do solo e da água, manejo integrado de insetospraga, doenças e plantas daninhas, valorização dos sistemas tradicionais de manejo dos

\footnotetext{
${ }^{41}$ Pierre-Nicolas Grisel, Renato Linhares de Assis, "Adoção de Práticas Agrícolas Sustentáveis: Estudo de Caso de um Sistema de Produção Hortícola Familiar em Ambiente de Montanha", Cadernos de Ciência \& Tecnologia, Brasília 29, 1 (2012): $133-158$

42 Antônio Carlos Frossard, 2014.

43 Gordon R. Conway, "The properties of agroecosystems", Agricultural systems 24, 2 (1987): 95-117
} 
recursos, redução da pressão antrópica na ocupação e uso de ecossistemas e ambientes frágeis, e adequação às novas exigências do mercado ${ }^{44}$.

Atualmente, o estado do Rio de Janeiro é o segundo maior produtor de hortaliças do país, produção essa em sua maior parte concentrada nas regiões serrana e sul, onde convive com a presença de várias Unidades de Conservação Ambiental ${ }^{45}{ }^{46}$. Em função disso, nestas regiões, há uma tendência à revalorização do rural, com áreas onde o maior grau de conservação da Mata Atlântica favorece, também, ao desenvolvimento do ecoturismo ${ }^{47}$.

Nesse contexto, ressalta-se o conceito de "ambientes de montanha" fluminenses ${ }^{48}$ que agrega a classificação de montanhas ${ }^{49} \operatorname{com}$ a definição de ambiente ${ }^{50}$. Sendo definido como áreas com elevações variando de 300 a 1.500 metros, onde as comunidades humanas estejam presentes, levando-se em conta seus valores, ambiente natural do entorno, assim como as expressões e atividades de forma geral em determinado contexto de tempo, destacando o ponto de vista antropocêntrico dessa definição, no qual o ser humano é considerado agente essencial no contexto. Pressupõe-se, portanto, que os ambientes de montanha das Regiões Serrana e Sul Fluminenses, pela forma de colonização, diversidade cultural, estrutura fundiária, condições técnicas e climáticas, oferecem condições para, não somente, formação de produtos únicos e característicos, mas também, uma diversidade produtiva que pode favorecer à maior eficiência e estabilidade na agricultura.

Desde o século XIX, o conhecimento colonial buscou desenvolver uma compartimentação da paisagem, espacializando as culturas de acordo com evidências topológicas e pedológicas, em uma busca da compreensão, exploração e formação

\footnotetext{
44 Luiz Carlos Balbino, Alexandre de Oliveira Barcellos, Luís Fernando Stone, Marco referencial: integração lavoura-pecuária-floresta (Brasília: EMBRAPA, 2011), 130p.

${ }^{45}$ Pierre-Nicolas Grisel, Renato Linhares de Assis, "Adoção de Práticas Agrícolas Sustentáveis: Estudo de Caso de um Sistema de Produção Hortícola Familiar em Ambiente de Montanha”, Cadernos de Ciência \& Tecnologia, Brasília 29, 1 (2012): 133-158

${ }^{46}$ Pierre-Nicolas Grisel, Renato Linhares de Assis, Dinâmica agrária da Região Sudoeste do município de Nova Friburgo e os atuais desafios de sua produção hortícola familiar (Seropédica: Embrapa Agrobiologia, Documentos, 299, 2015), 83p.

47 Paulo Roberto R. Alentejano, "A evolução do espaço agrário fluminense", Geographia 7, 13 (2005): 49-70.

${ }^{48}$ Amazile López Netto, Renato Linhares de Assis e Adriana Maria de Aquino, "Ações Públicas para o Desenvolvimento Rural Sustentável dos Ambientes de Montanha Brasileiros". Desenvolvimento em Questão 15, 39 (2017): 141-170.

49 Valerie Kapos, Jonathan Rhind, Mary Edwards, Martin F. Price and Corinna Ravilious, Developing a map of the world's mountain forests. In: M.F. Price and N. Butt (eds.) (2000) Forests in sustainable mountain development: A state-of knowledge report for 2000. (CAB International, Wallingford, 2000): p. 4-9.

50 Enrique Leff, Saber ambiental: sustentabilidade, racionalidade, complexidade, poder (Petrópolis: Vozes, 2001), 343 p.
} 
desses ambientes produtivos ${ }^{51}$. Nesse sentido, a agricultura fluminense busca continuar, após duzentos anos da sua implementação, a trajetória de desenvolvimento, aplicando experiências e o aprendizado herdados. Herança fortalecedora da capacidade presente de operacionalizar criativamente uma ação transformadora, com base nos vínculos de um legado do passado ${ }^{52}$. Onde as ações do passado vêm condicionar a propagação, continuidade e atualidade da atividade agrícola produtiva de alimentos ${ }^{53}$.

Para permitir a visualização dos resultados e sua discussão, foi elaborado por meio do software Q GIS (versão 3.4, madeira), onde utilizou-se sistemas de informações geográficas (SIG) em um modelo digital de elevação (MDE), com resolução de $90 \mathrm{~m}$ e projeção UTM (WGS 1984), formato: GEOTIFF (16 bits) ${ }^{54}$, o mapa visto na Figura 1. Este mapa mostra as cinco regiões do estado, seus 92 municípios e os respectivos relevos, com uma escala de altitudes. Onde, os 17 municípios mencionados no texto, foram identificados na legenda.

\footnotetext{
${ }^{51}$ Lucas Santa Cruz de Assis Brasil e Rogério Ribeiro de Oliveira, "About agricultural manuals, gardens and coffee plantations: mosaics and landscape transformation in the Paraiba do Sul Valley, Brazil", Historia Ambiental, Latinoamericana y Caribeña 10, 1 (2020): 278-305.

52 Héctor A. Alimonda, "Una herencia en manaos (anotaciones sobre história ambiental, ecología política y agroecología en una perspectiva latinoamericana)", Horizontes Antropológicos 12, 25 (2006): 237-255

${ }^{53}$ Carina Júlia Pensa Correa, Kelly Cristina Tonello, Ernest Nnadi e Alexandra Guidelli Rosa, "Semeando a cidade: histórico e atualidades da agricultura urbana", Ambiente \& Sociedade 23 (2020): 1-22.

${ }^{54}$ BRASIL, EMBRAPA - Empresa Brasileira de Pesquisa Agropecuária, 2019. Monitoramento por Satélite. Disponível em:

<https://www.cnpm.embrapa.br/projetos/relevobr/download/>. Acesso em: 4 jul. 2019.
} 
Figura 1. Mapa das regiões, com os municípios e relevo, do estado do Rio de Janeiro.

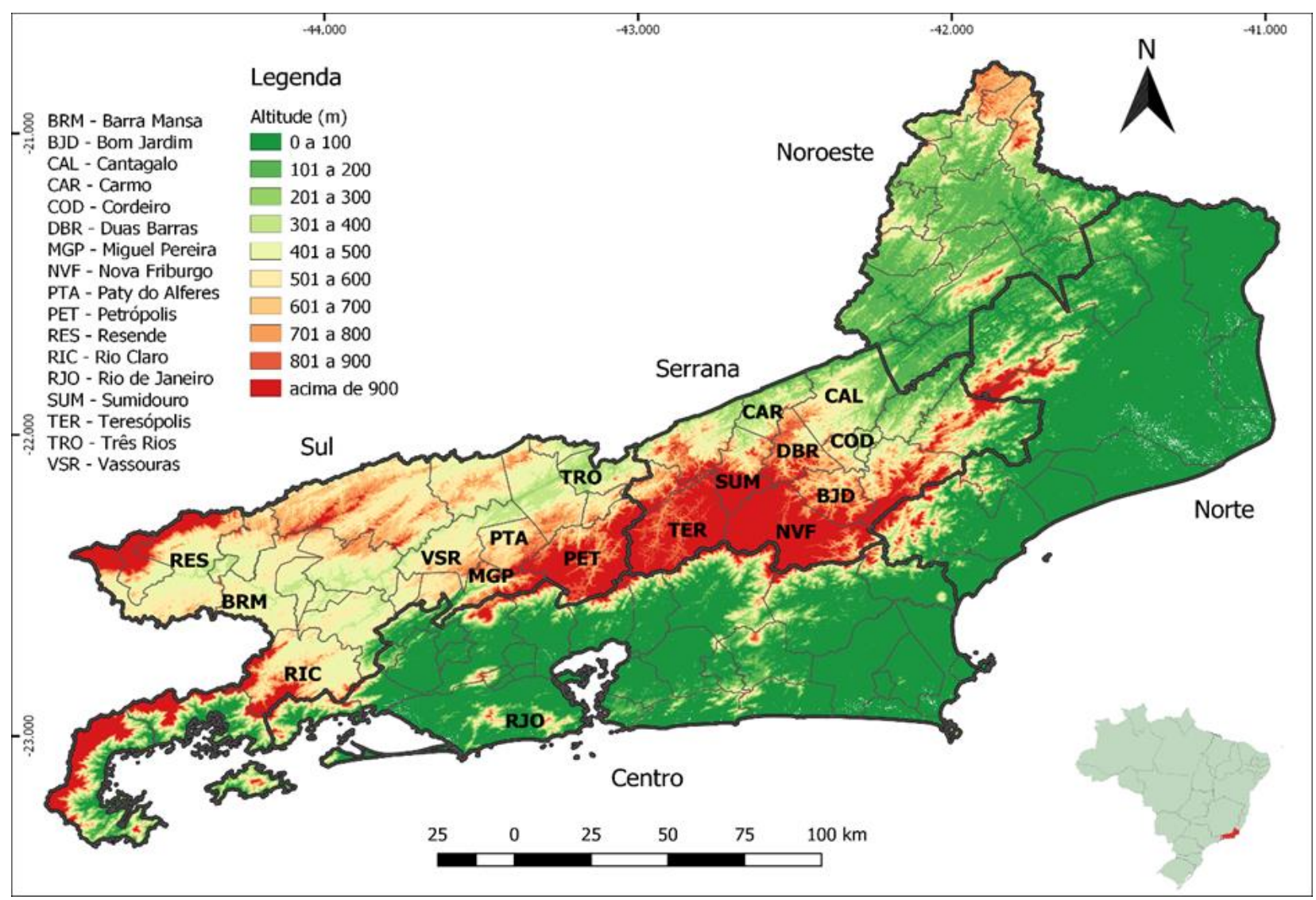

Fonte: Elaborado pelos autores.

Como consequência de todo esse processo histórico, no ano de 2018, segundo o Relatório de Acompanhamento Sistemático da Produção Agrícola - ASPA ${ }^{55}$, o estado do Rio de Janeiro apresentou uma área cultivada de 139.229,11 hectares (ha) e faturou 2.161.962.154,50 reais (RS). Somente com a atividade agrícola, foram colhidos 79 tipos de produtos ou itens diferentes, nos 86 municípios considerados produtores, dentro do total dos 92 que compõem o estado (Figura 1). Neste faturamento, em ordem decrescente, as culturas de tomate, cana de açúcar, abacaxi, café, aipim, alface e couve, contribuíram com 51\%. O município de Teresópolis, na região serrana, contribui com a maior participação no faturamento agrícola total anual do estado $(12,6 \%)$, ocupando posição de destaque (Figura 2). 
Figura 2. Paisagem vista da estrada RJ-130, Teresópolis, em outubro de 2016.

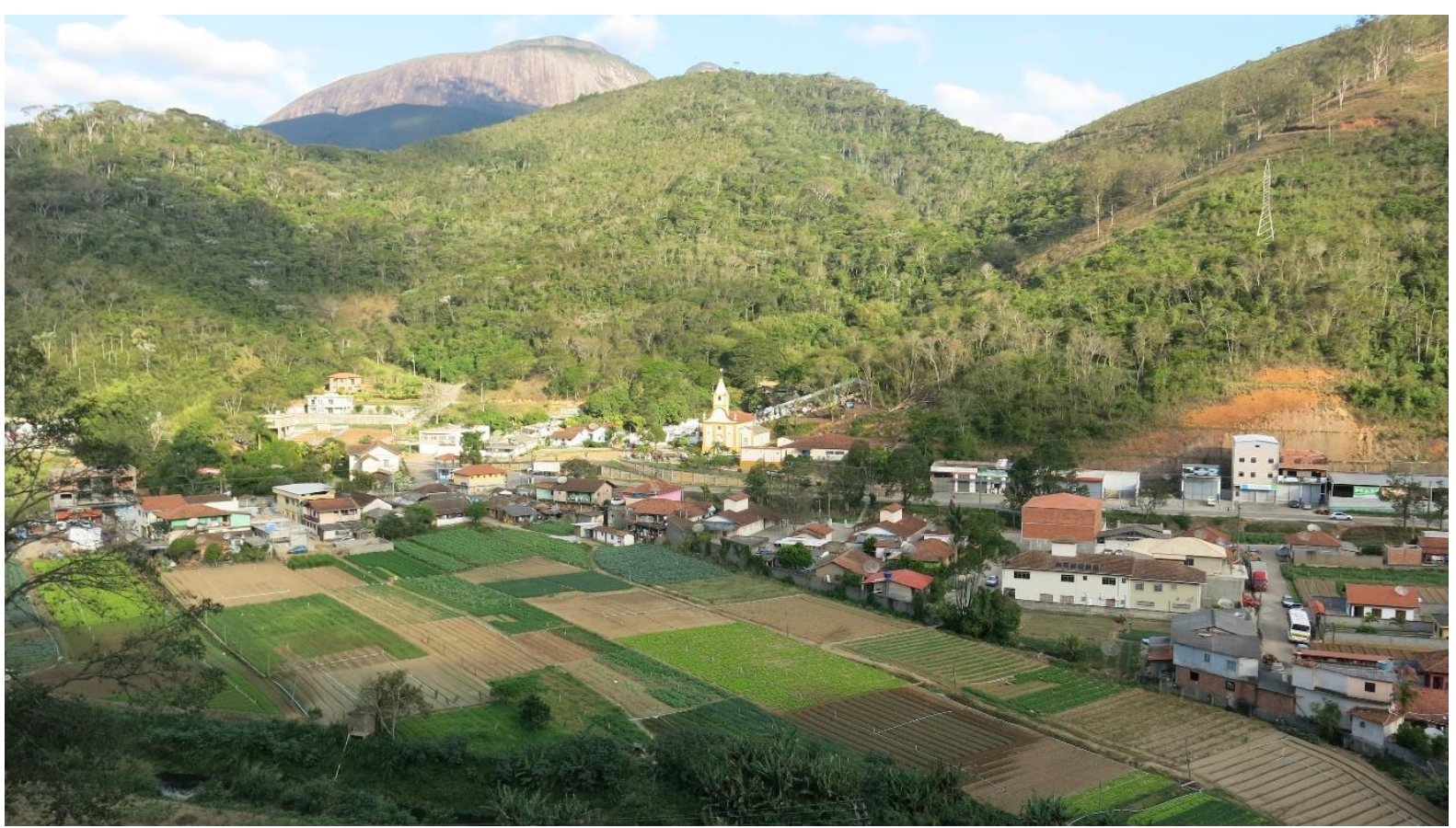

Fonte: Foto Elton de Oliveira

Considerando o faturamento por área colhida (R\$/ha), as regiões serrana e sul, onde estão localizados os ambientes de montanha do estado, apresentaram os melhores desempenhos anuais, entre 2010 e 2018 (Figura 3), segundo a série histórica dos relatórios ASPA $^{56}$. Foram também nestas regiões, que no ano de 2018, os municípios com maior diversidade produtiva, produziram 37, em Duas Barras, e 31 itens diferentes cada, em Sumidouro e Rio Claro. A diversidade produtiva pode fortalecer tanto a eficiência como a sustentabilidade da atividade agrícola ${ }^{57}$. Pode-se observar que a região serrana apresentou a maior diversidade produtiva (Tabela 2).

\footnotetext{
${ }^{56}$ BRASIL, EMATER-RIO - Empresa de Assistência Técnica e Extensão Rural do Estado do Rio de Janeiro. Relatório de Acompanhamento Sistemático da Produção Agrícola - ASPA, 2018. Disponível em: <http://www.emater.ri.gov.br/tecnica.asp>. Acesso em: 23 ago. 2019. 57 Vine Mutyasira, Dana Hoag, Dustin Pendell, Dale T. Manning, Melaku Berhe, "Assessing the relative sustainability of smallholder farming systems in Ethiopian highlands", Agricultural Systems, 167 (2018): 83-91.
} 
Tabela 2. Diversidade produtiva das regiões ao longo dos anos.

\begin{tabular}{llllllllllll}
\hline NÚMERO DE ITENS DIFERENTES PRODUZIDOS \\
\hline REGIÕES & 2010 & 2011 & 2012 & 2013 & 2014 & 2015 & 2016 & 2017 & 2018 & MÉDIA \\
\hline Centro & 44 & 47 & 46 & 46 & 50 & 52 & 53 & 54 & 55 & 49,7 \\
Noroeste & 34 & 45 & 37 & 39 & 41 & 38 & 36 & 47 & 45 & 40,2 \\
Norte & 37 & 35 & 33 & 37 & 37 & 38 & 37 & 37 & 38 & 36,6 \\
Serrana & 52 & 53 & 50 & 51 & 52 & 53 & 52 & 54 & 59 & 52,9 \\
Sul & 49 & 45 & 46 & 50 & 49 & 50 & 52 & 53 & 51 & 49,4 \\
\hline
\end{tabular}

Fonte: Elaborado pelos autores, com os dados EMATER-RIO, $2018^{58}$.

As regiões serrana e sul, juntas, comportaram 20,7\% da área total cultivada e 48,2\% do faturamento agrícola, de todo o estado do Rio de Janeiro, no ano de 2018. Portanto, essas duas regiões não são detentoras da maioria das áreas cultivadas no estado. No entanto, pode-se verificar que essas mesmas regiões, que possuem altitudes acima de $300 \mathrm{~m}$ e agricultura em ambientes de montanha, apresentaram os maiores faturamentos (RS) por área cultivada em hectares (Figuras 1 e 3) e, também, os municípios com maior diversidade produtiva.

Figura 3. Gráfico do desempenho da agricultura ao longo dos anos, das cinco regiões do estado do Rio de Janeiro, mostrando o faturamento $(R \$)$ por área cultivada (ha).

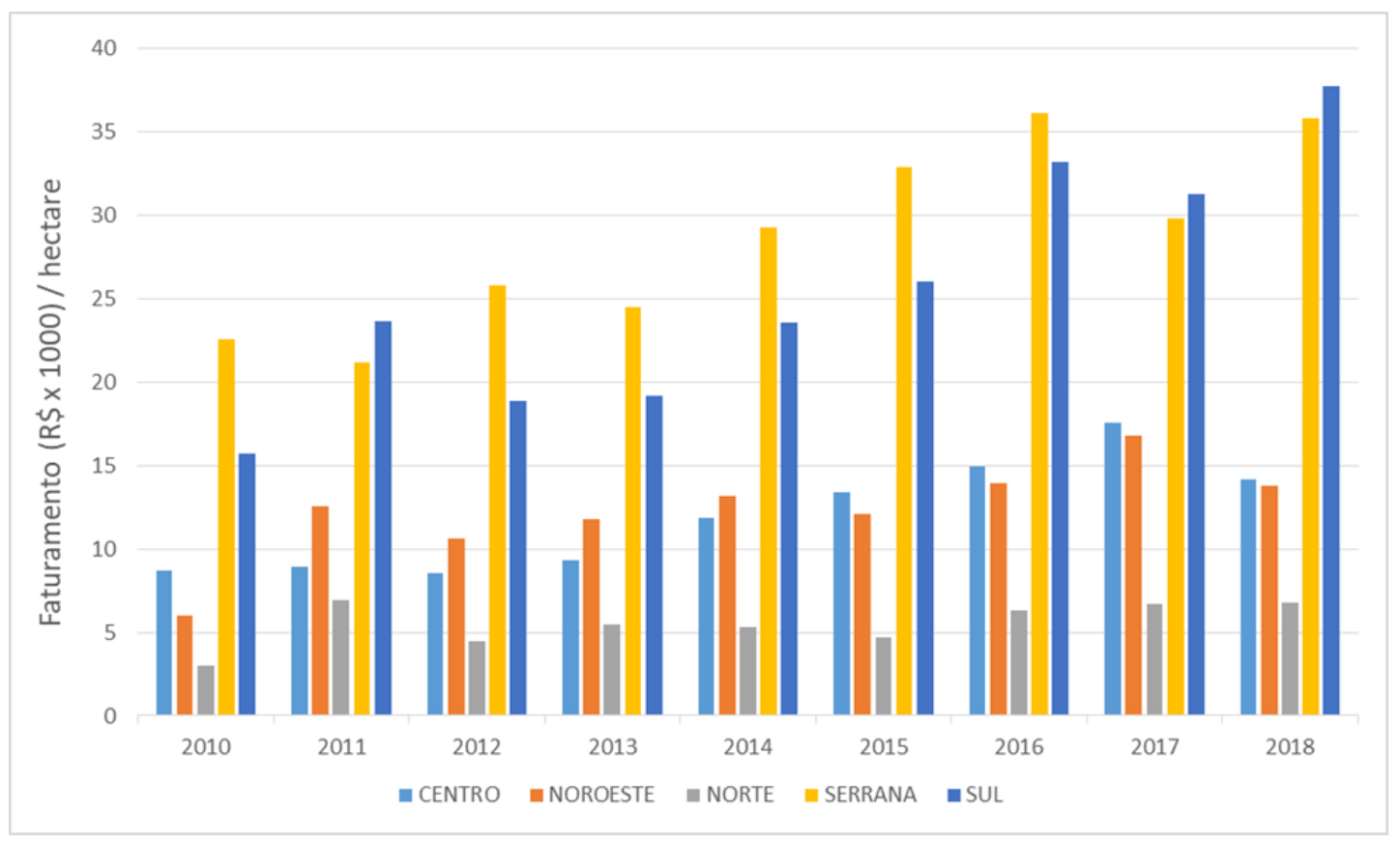

58 BRASIL, EMATER-RIO - Empresa de Assistência Técnica e Extensão Rural do Estado do Rio de Janeiro. Relatório de Acompanhamento Sistemático da Produção Agrícola - ASPA, 2018. Disponível em: <http://www.emater.ri.gov.br/tecnica.asp>. Acesso em: 23 ago. 2019. 
Fonte: Elaborado pelos autores, com os dados EMATER-RIO, $2018^{59}$.

A região serrana, centro e sul apresentaram as maiores diversidades produtivas (Tabela 2) e os melhores desempenhos, com distinção das regiões serrana e sul (Figura 3). Esta tendência destaca a diversidade produtiva como promotora do desempenho na agricultura $^{60}{ }^{61}$. Pode-se verificar na literatura uma relação positiva entre agrobiodiversidade ${ }^{62}$ e produtividade agrícola ${ }^{63}$. A biodiversidade pode desempenhar um papel benéfico no apoio à lucratividade do produtor rural ${ }^{64}$.

A comparação do desempenho da agricultura em diferentes ambientes e localizações geográficas pode contribuir para avaliar e classificar as diferentes regiões produtoras agrícolas, fornecendo subsídios para a intervenção, definição de estratégias, direcionamento de ações, políticas de monitoramento e desenvolvimento da agricultura $^{65}$.

\section{CONSIDERAÇÕES FINAIS}

Nos últimos duzentos anos, o desenvolvimento da agricultura fluminense foi concebido dentro de uma diversidade de ambientes, culturas, pessoas, espécies vegetais, estratégias, políticas e situações econômicas que moldaram a sua conformação atual. Ao longo da história agroambiental das regiões montanhosas fluminenses, a agricultura foi praticada na forma de subsistência pelos índios e nativos, seguida pelas monoculturas dos colonizadores portugueses e mão de obra dos

\footnotetext{
${ }^{59}$ BRASIL, EMATER-RIO - Empresa de Assistência Técnica e Extensão Rural do Estado do Rio de Janeiro. Relatório de Acompanhamento Sistemático da Produção Agrícola - ASPA, 2018. Disponível em: <http://www.emater.ri.gov.br/tecnica.asp>. Acesso em: 23 ago. 2019. ${ }^{60}$ Elton de Oliveira, Adriana Maria de Aquino, Renato Linhares de Assis, João Carlos Correia Baptista Soares de Mello, "Horticultores agroecológicos em ambientes de montanha do município de Teresópolis, Rio de Janeiro", Revista Verde de Agroecologia e Desenvolvimento Sustentável 14, 2 (2019): 273-280

${ }^{61}$ Regina Helena Rosa Sambuichi, Ernesto Pereira Galindo, Michel Ângelo Constantino de Oliveira, Rodrigo Mendes Pereira, A diversificação produtiva como forma de viabilizar o desenvolvimento sustentável da agricultura familiar no brasil. In: Brasil em desenvolvimento 2014: estado, planejamento e políticas públicas. Brasília - Ipea 2, 3 (2014): 61-84.

62 BRASIL, MMA - Ministério do Meio Ambiente. Agrobiodiversidade, (2017). Disponível em: <http://www.mma.gov.br/biodiversidade/conservacaoe-promocao-do-uso-da-diversidade-genetica/agrobiodiversidade>. Acesso em: 04 out. 2018.

${ }^{63}$ Amani Omer, Unai Pascual, Noel Russell, "A theoretical model of agrobiodiversity as a supporting service for sustainable agricultural intensification". Ecological Economics 69, 10 (2010): 1926-1933.

64 Thomas M. Van Rensburg, Elias Mulugeta, "Profit efficiency and habitat biodiversity: The case of upland livestock farmers in Ireland", Land Use Policy 54 (2016): 200-211.

65 Elena Toma, Carina Dobre, Ion Dona, Elena Cofas, "DEA applicability in assessment of agriculture efficiency on areas with similar geographically patterns", Agriculture and Agricultural Science Procedia 06 (2015): 704-711
} 
africanos, pelos horticultores europeus. Todo este processo foi intensificado e propiciado pelo contexto histórico destacado nesse trabalho, tendo como resultado da sua trajetória histórica, um melhor desempenho produtivo dessas regiões montanhosas, quando comparado com as demais do estado.

Portanto, essas regiões que apresentam o maior faturamento por unidade de área cultivada, juntamente com a maior variedade de cultivos diferentes, dentro do estado do Rio de Janeiro, exaltam sua agrobiodiversidade construída ao longo do tempo. Evidenciando, nos ambientes de montanha fluminenses, "as derivações e transmutações desses lugares, a partir da construção de vida em sociedade com a natureza, pela milenar ação humana, transformam seu ecossistema em paisagem com história"66, resultante da interação de seres humanos com o ecossistema.

Dessa forma, a história agroambiental aqui destacada ajuda a explicar a formação desse território e entender a sua dinâmica. Percebe-se que o desenvolvimento desses ambientes de produção agrícola diversificada, com uma estrutura agrária e dinâmica produtiva, características dos ambientes de montanha fluminenses, contribuiu para o desempenho da sua agricultura.

\section{AGRADECIMENTOS}

Em memória do Professor Héctor Alimonda (1949-2017), pela dedicação ao tema. Agradecimentos à Casa Suíça - Memorial da Colonização, Fundação D. João VI de Nova Friburgo-RJ e Biblioteca Nacional - RJ, Brasil, pelos acessos à pesquisa documental e bibliográfica.

\section{REFERÊNCIAS}

Afonso de Escragnolle Taunay, Pequena História do Café no Brasil (1727-1937), (Rio de Janeiro: Departamento Nacional do Café, 1945), 558p.

${ }^{66}$ Rogério Ribeiro de Oliveira, Carlos Engemann, "História da paisagem e paisagens sem história: a presença humana na Floresta Atlântica do Sudeste Brasileiro", Revista Esboços 18, 25 (2011): 9-31. 
Agenor de Roure, "O Centenário de Nova Friburgo", Revista do Instituto Histórico Geographico Brasileiro 83 (1918): 243-266.

Amani Omer, Unai Pascual, Noel Russell, "A theoretical model of agrobiodiversity as a supporting service for sustainable agricultural intensification". Ecological Economics 69, 10 (2010): 1926-1933.

Amazile López Netto, Renato Linhares de Assis e Adriana Maria de Aquino, "Ações Públicas para o Desenvolvimento Rural Sustentável dos Ambientes de Montanha Brasileiros". Desenvolvimento em Questão 15, 39 (2017): 141-170.

Antonio Carlos Frossard, "Pedagogia da alternância e articulação dos agentes formativos de técnicos em agropecuária: interação entre educação do campo e desenvolvimento rural sustentável em Nova Friburgo (Brasil) e Lobos (Argentina)" (Tese de Doutorado em Ciência Tecnologia e Inovação em Agropecuária, Universidade Federal Rural do Rio de Janeiro - UFRRJ, 2014)

Armando Cypriano Pires, "Dados, Fatos e Falas: Histórias "contadas" sobre Saúde e Trabalho" (Dissertação de Mestrado, Escola Nacional de Saúde Pública Sergio Arouca ENSP - FIOCRUZ, Rio de Janeiro, 1996)

BRASIL, EMATER-RIO - Empresa de Assistência Técnica e Extensão Rural do Estado do Rio de Janeiro. Relatório de Acompanhamento Sistemático da Produção Agrícola ASPA, 2018. Disponível em: <http://www.emater.rj.gov.br/tecnica.asp>. Acesso em: 23 ago. 2019.

BRASIL, EMBRAPA - Empresa Brasileira de Pesquisa Agropecuária. Conceito de Agrobiodiversidade, 2019. Disponível em: <https://www.embrapa.br/contandociencia/agricultura/-/asset_publisher/FcDEMJIbvFle/content/o-que-eagrobiodiversidade-/1355746? inheritRedirect=false>. Acesso em: 21fev. 2019.

BRASIL, EMBRAPA - Empresa Brasileira de Pesquisa Agropecuária, 2019. Monitoramento por Satélite. Disponível em: <https://www.cnpm.embrapa.br/projetos/relevobr/download/>. Acesso em: 4 jul. 2019.

BRASIL, MMA - Ministério do Meio Ambiente. Agrobiodiversidade, (2017). Disponível em: <http://www.mma.gov.br/biodiversidade/conservacao-e-promocao-do-usoda-diversidade-genetica/agrobiodiversidade>. Acesso em: 04 out. 2018.

Carina Júlia Pensa Correa, Kelly Cristina Tonello, Ernest Nnadi e Alexandra Guidelli Rosa, "Semeando a cidade: histórico e atualidades da agricultura urbana", Ambiente \& Sociedade 23 (2020): 1-22.

Carlos Rodolpho Fischer, Uma História em Quatro Tempos (Nova Friburgo: Fábrica de Rendas Arp S.A, 1986), 142p.

Celso Furtado, Formação Econômica do Brasil (São Paulo: Companhia Editora Nacional, 1959), 242p. 
Cristiano Mascaro, Tasso Fragoso Pires, Mary del Priore, Roberto Conduru, Marta Fadel, Fazendas do Império, (Rio de Janeiro: Edições Fadel, 2010), 312p.

Elena Toma, Carina Dobre, Ion Dona, Elena Cofas, "DEA applicability in assessment of agriculture efficiency on areas with similar geographically patterns", Agriculture and Agricultural Science Procedia 06 (2015): 704-711

Elton de Oliveira, Adriana Maria de Aquino, Renato Linhares de Assis, João Carlos Correia Baptista Soares de Mello, "Horticultores agroecológicos em ambientes de montanha do município de Teresópolis, Rio de Janeiro", Revista Verde de Agroecologia e Desenvolvimento Sustentável 14, 2 (2019): 273-280

Enrique Leff, Saber ambiental: sustentabilidade, racionalidade, complexidade, poder (Petrópolis: Vozes, 2001), 343 p.

Eric John Ernest Hobsbawm, A era das revoluções: Europa, 1789-1848 (Rio de Janeiro: Paz e Terra, 1989), 532p.

Gordon R. Conway, "The properties of agroecosystems", Agricultural systems 24, 2 (1987): 95-117

Héctor A. Alimonda, "Una herencia en manaos (anotaciones sobre história ambiental, ecología política y agroecología en una perspectiva latinoamericana)", Horizontes Antropológicos 12, 25 (2006): 237-255

Humberto Fernandes Machado, Escravos, Senhores e Café. A Crise da Cafeicultura Escravista do Vale do Paraíba Fluminense, 1860-1888 (Niterói: Clube de Literatura Cromos, 1993), 144p.

João Manuel Cardoso de Mello, O Capitalismo Tardio (São Paulo: Editora Brasiliense, 1982), 182p.

José Augusto Pádua, Um Sopro de Destruição: pensamento político e crítica ambiental no Brasil escravista (1786-1888) (Rio de Janeiro: Zahar, 2002), 318p.

Jules Conus, História da Emigração Friburguense para o Brasil, 1819 a 1820. Trad. José Cortes Coutinho (Nova Friburgo: Typographya da Sociedade Editora e Impressora de Friburgo, 1918), 34p.

Laurentino Gomes, 1808: Como uma rainha louca, um príncipe medroso e uma corte corrupta enganaram Napoleão e mudaram a História de Portugal e do Brasil (São Paulo: Ed. Globo, 2014), 382p.

Lígia Osorio Silva, Terras Devolutas e Latifúndio: Efeitos da Lei de 1850 (Campinas: Editora da UNICAMP, 1996), 373p.

Lucas Santa Cruz de Assis Brasil e Rogério Ribeiro de Oliveira, "About agricultural manuals, gardens and coffee plantations: mosaics and landscape transformation in the 
Paraiba do Sul Valley, Brazil", Historia Ambiental, Latinoamericana y Caribeña 10, 1 (2020): 278-305.

Luís Henrique Menezes Fernandes, Um Governo de Engonços: Metrópole e Sertanistas na Expansão dos Domínios Portugueses aos Sertões do Cuiabá (1721-1728) (Curitiba: Editora Prismas, 2015), 197p.

Luiz Carlos Balbino, Alexandre de Oliveira Barcellos, Luís Fernando Stone, Marco referencial: integração lavoura-pecuária-floresta (Brasília: EMBRAPA, 2011), 130p.

Maria Janaina Botelho Corrêa, Histórias e memória de Nova Friburgo (Rio de Janeiro: Educam, 2011), 448p.

Nicolau Joaquim Moreira, Indicações agrícolas para os imigrantes que se dirigem ao Brasil (Rio de Janeiro: Imperial Instituto Artístico, 1875).

Paulo Roberto R. Alentejano, "A evolução do espaço agrário fluminense", Geographia 7, 13 (2005): 49-70.

Pedro Cúrio, Como surgiu Friburgo (Esboço Histórico e Episódico) - 1818-1840 (SEDEGRA S/A, 1974), 176p.

Pierre-Nicolas Grisel, "La possibilité dúne transition agroécologique: Une analyse des déterminants économiques, écologiques et institutionnels de l'adoption de pratiques agricoles alternatives dans une communauté a'agriculteurs familiaux au Brésil" (Tese de Doutorado, Paris, Université de Versailles Saint Quentin en Yvelines, 2013).

Pierre-Nicolas Grisel, Renato Linhares de Assis, "Adoção de Práticas Agrícolas Sustentáveis: Estudo de Caso de um Sistema de Produção Hortícola Familiar em Ambiente de Montanha", Cadernos de Ciência \& Tecnologia, Brasília 29, 1 (2012): 133158

Pierre-Nicolas Grisel, Renato Linhares de Assis, Dinâmica agrária da Região Sudoeste do município de Nova Friburgo e os atuais desafios de sua produção hortícola familiar (Seropédica: Embrapa Agrobiologia, Documentos, 299, 2015), 83p.

Regina Helena Rosa Sambuichi, Ernesto Pereira Galindo, Michel Ângelo Constantino de Oliveira, Rodrigo Mendes Pereira, A diversificação produtiva como forma de viabilizar o desenvolvimento sustentável da agricultura familiar no brasil. In: Brasil em desenvolvimento 2014: estado, planejamento e políticas públicas. Brasília - Ipea 2, 3 (2014): 61-84.

Rogério Ribeiro de Oliveira, Carlos Engemann, "História da paisagem e paisagens sem história: a presença humana na Floresta Atlântica do Sudeste Brasileiro", Revista Esboços 18, 25 (2011): 9-31.

Rubens Onofre Nodari, Miguel Pedro Guerra, "A agroecologia: estratégias de pesquisa e valores", Estudos Avançados 29, 83 (2015): 183-207. 
Stanley Stein, Grandeza e Decadência do Café no Vale do Paraíba (São Paulo: Editora Brasiliense, 1961), 372p.

Thomas M. Van Rensburg, Elias Mulugeta, "Profit efficiency and habitat biodiversity: The case of upland livestock farmers in Ireland", Land Use Policy 54 (2016): 200-211.

Thomé Maria de Fonseca e Silva, "Breve Notícia sobre a Colônia de Suiços fundada em Nova Friburgo", Revista Trimensal de História e Geographia 5, XII, 14 (1849): 136-142.

Valerie Kapos, Jonathan Rhind, Mary Edwards, Martin F. Price and Corinna Ravilious, Developing a map of the world's mountain forests. In: M.F. Price and N. Butt (eds.) (2000) Forests in sustainable mountain development: A state-of knowledge report for 2000. (CAB International, Wallingford, 2000): p. 4-9.

Vine Mutyasira, Dana Hoag, Dustin Pendell, Dale T. Manning, Melaku Berhe, "Assessing the relative sustainability of smallholder farming systems in Ethiopian highlands", Agricultural Systems, 167 (2018): 83-91.

Wilson Vieira, "Apogeu e decadência da cafeicultura fluminense (1860 - 1930)" (Dissertação de Mestrado em História Econômica - Universidade Estadual de Campinas -UNICAMP, 2000).

\title{
History, present and productive performance of agriculture in Rio de Janeiro
}

\begin{abstract}
In the same period of the 1800s, two land policies started the creation process of agriculture in the Rio de Janeiro mountainous regions. A literature search and an analysis of quantitative data on current agricultural production were carried out to historically contextualize the development of agriculture and to evaluate its productive performance. It was found that the development of this activity was generated within a diversity of environments, people, plant species, strategies, policies and economic situations that contributed to shape its current conformation, with differentiated characteristics, agrarian dynamics and performance. It was identified that the mountain and southern regions had the highest revenue per hectare and the municipalities with the greatest productive diversity.
\end{abstract}

Keywords: agroenvironmental history; mountain environments; agrobiodiversity. 